\title{
TU/e Emonowen

\section{Modification of the collective Thomson scattering radiometer in the search for parametric decay on TEXTOR}

\section{Citation for published version (APA):}

Nielsen, S. K., Salewski, M., Bongers, W., Korsholm, S. B., Leipold, F., Meo, F., Michelsen, P. K., Moseev, D., Oosterbeek, J. W., Stejner, M., \& Westerhof, E. (2012). Modification of the collective Thomson scattering radiometer in the search for parametric decay on TEXTOR. Review of Scientific Instruments, 83, 113508-1/5. [113508]. https://doi.org/10.1063/1.4768668

DOI:

10.1063/1.4768668

Document status and date:

Published: 01/01/2012

\section{Document Version:}

Publisher's PDF, also known as Version of Record (includes final page, issue and volume numbers)

\section{Please check the document version of this publication:}

- A submitted manuscript is the version of the article upon submission and before peer-review. There can be important differences between the submitted version and the official published version of record. People interested in the research are advised to contact the author for the final version of the publication, or visit the $\mathrm{DOI}$ to the publisher's website.

- The final author version and the galley proof are versions of the publication after peer review.

- The final published version features the final layout of the paper including the volume, issue and page numbers.

Link to publication

\section{General rights}

Copyright and moral rights for the publications made accessible in the public portal are retained by the authors and/or other copyright owners and it is a condition of accessing publications that users recognise and abide by the legal requirements associated with these rights.

- Users may download and print one copy of any publication from the public portal for the purpose of private study or research.

- You may not further distribute the material or use it for any profit-making activity or commercial gain

- You may freely distribute the URL identifying the publication in the public portal.

If the publication is distributed under the terms of Article 25fa of the Dutch Copyright Act, indicated by the "Taverne" license above, please follow below link for the End User Agreement:

www.tue.nl/taverne

Take down policy

If you believe that this document breaches copyright please contact us at:

openaccess@tue.nl

providing details and we will investigate your claim. 


\title{
Modification of the collective Thomson scattering radiometer in the search for parametric decay on TEXTOR
}

\author{
S. K. Nielsen, ${ }^{1}$ M. Salewski, ${ }^{1}$ W. Bongers, ${ }^{2}$ S. B. Korsholm, ${ }^{1}$ F. Leipold, ${ }^{1}$ F. Meo, ${ }^{1}$ \\ P. Michelsen, ${ }^{1}$ D. Moseev, ${ }^{2}$ J. W. Oosterbeek, ${ }^{3}$ M. Stejner, ${ }^{1}$ and E. Westerhof ${ }^{2}$ \\ ${ }^{1}$ Association EURATOM - DTU, Department of Physics, Technical University of Denmark, Risoe Campus, \\ DK-4000 Roskilde, Denmark \\ ${ }^{2}$ FOM Institute DIFFER, Dutch Institute for Fundamental Energy Research, Association EURATOM - FOM, \\ Nieuwegein, The Netherlands \\ ${ }^{3}$ Department of Applied Physics, Science and Technology of Nuclear Fusion, Eindhoven University of \\ Technology, NL-5600 MB Eindhoven, Netherlands
}

(Received 19 July 2012; accepted 26 October 2012; published online 29 November 2012)

\begin{abstract}
Strong scattering of high-power millimeter waves at $140 \mathrm{GHz}$ has been shown to take place in heating and current-drive experiments at TEXTOR when a tearing mode is present in the plasma. The scattering signal is at present supposed to be generated by the parametric decay instability. Here we describe the heterodyne detection system used to characterize the newly discovered signal measured at TEXTOR, and we present spectral shapes in which the signal can appear under different conditions. The radiation is collected by the receiver through a quasi-optical transmission line that is independent of the electron cyclotron resonance heating transmission line, and so the scattering geometry is variable. The signal is detected with 42 frequency channels ranging from 136 to $142 \mathrm{GHz}$. We demonstrate that the large signal does not originate from gyrotron spurious radiation. The measured signal agrees well with independent backscattering radiometer data. [http://dx.doi.org/10.1063/1.4768668]
\end{abstract}

\section{INTRODUCTION}

The tokamak is presently the most promising device for obtaining a net energy gain from thermonuclear fusion on earth. ${ }^{1}$ The capability to control the current profile in a tokamak is both important to obtain high performance plasmas and to control and suppress a number of instabilities, for example sawtooth oscillations and tearing modes. ${ }^{2}$ Tearing modes, and especially neoclassical tearing modes, pose a threat to the operation of future tokamak power plants. Several systems are being developed to detect and control such modes. On the tokamak experiment for technology oriented research (TEXTOR: major radius $R=1.75 \mathrm{~m}$, minor radius $a=0.46 \mathrm{~m}),{ }^{3}$ a feedback system has successfully demonstrated the suppression of tearing modes using microwaves. ${ }^{4}$ However, in specific electron density intervals, the system recorded large unexplained perturbations which could hamper the proper working of the feedback loop. ${ }^{5}$

In the TEXTOR feedback system an electron cyclotron emission (ECE) radiometer detects the mode, and an electron cyclotron resonance heating (ECRH) system, using a $140 \mathrm{GHz}$ gyrotron, suppresses it by heating and driving a current in the island O-point. Because the ECRH and ECE systems use the same transmission line the (inline) radiometer is also sensitive to backscattering radiation. The backscattering cross section is, however, very low, so the backscattering was not expected to interfere with the detection of the mode. The parametric decay instability, 6,7 in which the main heating beam decays into two daughter waves, could in principle generate signals large enough to disturb the feedback loop but this was not considered possible due to the low gyrotron power.

The spectral power density recorded for certain electron densities was, however, so large that several channels of the six-channel radiometer saturated and gain compression occurred in the intermediate frequency (IF) amplifier. In order to study this anomalous signal in detail, we applied the radiometer used for the collective Thomson scattering (CTS) diagnostic ${ }^{8}$ which was modified to detect high power radiation in a frequency range similar to that of the feedback radiometer. Unlike for the in-line radiometer, the CTS receiver geometry is adjustable which allows a spatial investigation. Additionally, a new spectrometer was connected to the inline system antenna through a $3 \mathrm{~dB}$ splitter. ${ }^{9,10}$ By combining these two radiometers, a detailed study of the anomalous signal was undertaken. ${ }^{11}$ The observations have been suggested to originate from the parametric decay instability and has motivated a re-evaluation of the parametric decay instability power threshold. ${ }^{12-15}$

In this article we describe the modified CTS radiometer used to detect the newly discovered strong signals during ECRH operation. The calibration of the system is discussed, and examples of time resolved measurements of strong signal in the presence of tearing modes are shown for different plasma densities. We demonstrate here that the anomalous signal is not a result of gyrotron stray radiation by changing the radiometer view during continuous wave $(\mathrm{CW})$ gyrotron operation. Finally the measured signals are compared with the measurements of the in-line radiometer.

\section{RECEIVER SETUP AND CALIBRATION}

The TEXTOR fast-ion CTS diagnostic is designed for studying the time-resolved dynamics of the $1 \mathrm{D}$ fast-ion velocity space distribution function. ${ }^{16-19}$ This is done by detecting the scattered radiation from $107 \mathrm{GHz}$ to $113 \mathrm{GHz}$ when using 
focused radiation from a $110 \mathrm{GHz}$ gyrotron as a probe beam. The CTS receiver is optimized to detect low spectral power density levels (in the order of $1 \mathrm{eV}$ ) in the presence of a relatively high background level $(20-100 \mathrm{eV})$ and with a stray radiation level at the probe frequency which is many orders of magnitude higher.

In the experiments reported here, we use the CTS radiometer to detect radiation in the frequency range 136-142 GHz. Therefore the front end of the receiver consisting of notch filters, a high pass filter, and a mixing stage were replaced. The radiation from the plasma passes through a quasi-optical transmission line. The plasma facing mirror of the receiver is movable and is located approximately $20 \mathrm{~cm}$ above the gyrotron launcher. The receiver line of sight can be modified during a plasma discharge to intersect the gyrotron beam at a specific radial position. The receiver transmission line is equipped with a universal polarizer which allows the receiver to be sensitive to radiation with different polarizations such as $\mathrm{O}$-mode or $\mathrm{X}$-mode or mixtures thereof. ${ }^{20} \mathrm{~A}$ schematic diagram of the receiver is shown in Fig. 1. The radiation is collected by a horn and fed through two $140 \mathrm{GHz}$ notch filters using fundamental waveguides. The stop band of the notch filters blocks the gyrotron stray radiation in the tokamak and in the tokamak hall. The notch filters are followed by a high pass filter which attenuates frequencies below $130 \mathrm{GHz}$. The signal is then mixed down using a back-wave oscillator at a frequency of $129.46 \mathrm{GHz}$. The receiver com-

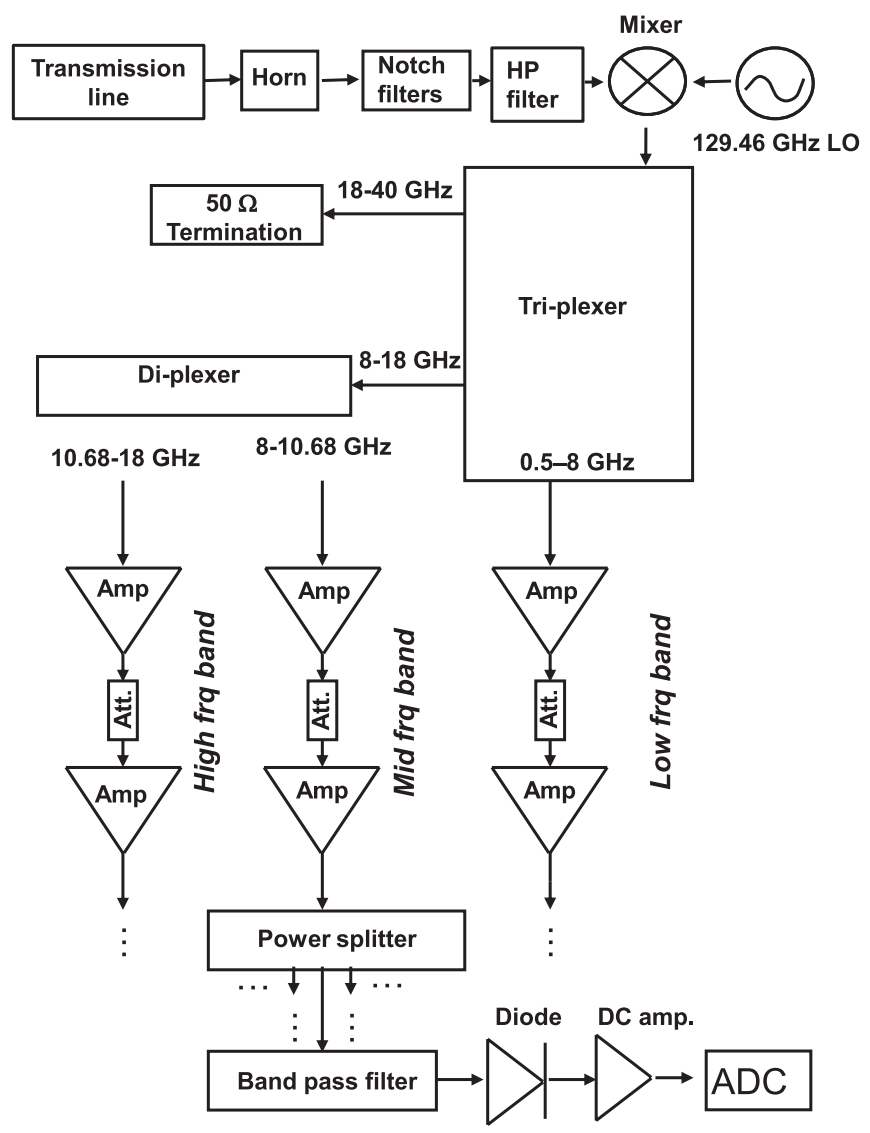

FIG. 1. Schematic diagram of the modified TEXTOR CTS receiver. Only the front end of the receiver (top row in the diagram) is modified compared to standard CTS operation. ponents in the remainder of the transmission line are original parts of the fast-ion CTS receiver. In the IF stage the radiation is split up in a low frequency band $(0.5-8 \mathrm{GHz})$, a middle frequency band $(8-10.68 \mathrm{GHz})$, and a high frequency band $(10.68-18 \mathrm{GHz})$. After this frequency division, the signal is amplified in two stages by low noise IF amplifiers. The signal is then divided and fed into bandpass filters defining the various frequency channels. The 32 channels in the middle band have widths of $80 \mathrm{MHz}$ each. In the low- and high-frequency bands, the widths vary from $120 \mathrm{MHz}$ to $750 \mathrm{MHz}$ giving a complete coverage from $6.1 \mathrm{GHz}$ to $12.9 \mathrm{GHz}$. This corresponds to radiation of 135.6 to $142.4 \mathrm{GHz}$ leaving the plasma at the horn antenna. The diodes after the band pass filters convert the signal into dc, and then the signal is amplified. This signal is finally recorded by six synchronized NI-4472 cards. Each card consists of 8 ADC's with 24 bit resolution and a maximum sampling rate of $100 \mathrm{kHz}$. The ADC's operate in the voltage range $-10 \mathrm{~V}$ to $+10 \mathrm{~V}$ which sets the bit noise level to around $1 \mu \mathrm{V}$.

In the measurements reported here, a rotating island crosses the second harmonic resonance layer of the X-mode ECRH heating. Under some conditions a large number of CTS channels saturate. No indication of gain compression is observed. Two additional attenuation units, consisting of $2 \mathrm{~cm}$ thick books, are inserted in front of the receiver horn in order to avoid saturation. The attenuation units are calibrated by viewing the passive radiation emitted from the plasma, and the attenuation of each unit is estimated to $12 \mathrm{~dB}$. Variation in ambient humidity is ignored as the calibration of the attenuation units was performed shortly before the discharge.

When the attenuation units are included in the transmission line, the ECE level is comparable with the receiver noise level. The receiver without additional attenuation units is calibrated by viewing a cold ECE resonance close to the plasma center. The receiver was set to accept primarily O-mode with a radial view and was cross-calibrated to the ECE and incoherent Thomson scattering diagnostics. The calibration factors for the system without additional attenuation are shown in Fig. 2. The large variation in the calibration factors can partly be explained by variation in the channel bandwidths.

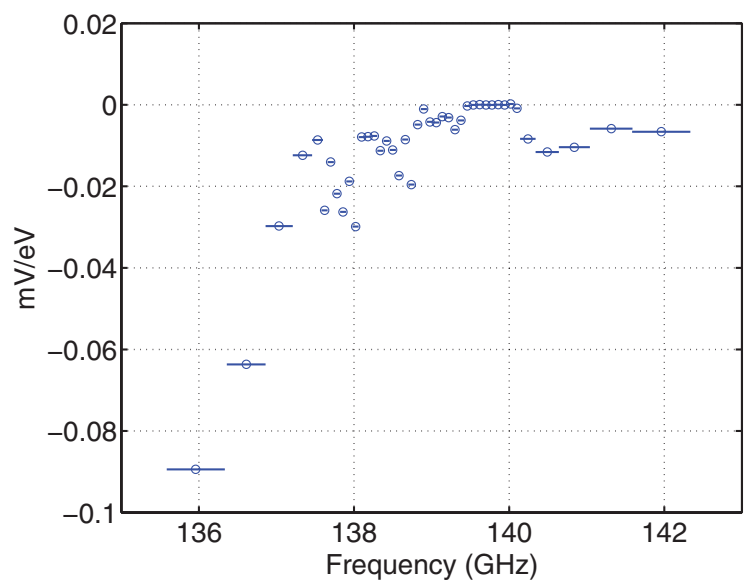

FIG. 2. Calibration curve for the CTS receiver without attenuation units. The horizontal lines represent the bandwidth of each channel. The notch filer covers 139.5 to $140 \mathrm{GHz}$ resulting in $0 \mathrm{mV} / \mathrm{eV}$. 
The frequency shape of the calibration was verified in a separate discharge with a cold second harmonic EC resonance (X-mode) at the plasma edge. The absolute level of the entire system, i.e., the calibration factors from Fig. 2 with additionally two attenuation units, was evaluated in a discharge with the cold second harmonic EC resonance (X-mode) close to the plasma center. A few channels in the modified CTS receiver showed a signal level larger than the receiver noise level, and the calibrated data agreed with the data from the ECE diagnostic within the errorbars.

\section{RESULTS}

When the plasma is heated by ECRH, highly structured signals are observed in discharges with sawtooth or tearing mode activity. This has previously been reported. ${ }^{11,21}$ The signals are very dependent on the electron density. In Fig. 3, a contour plot of the calibrated CTS receiver signal shows strong scattering in the presence of a rotating island. The island is generated by the dynamic ergodic divertor (DED), ${ }^{22}$ and its rotation frequency is controlled to be $974 \mathrm{~Hz}$ by locking its rotation to the current in the DED coils. The O-point of the island intersects the gyrotron beam at approximately $t$ $=2.081 \mathrm{~s}, 2.082 \mathrm{~s}, 2.083 \mathrm{~s}$, and $2.084 \mathrm{~s}$. The receiver mirrors are arranged such that the receiver line of sight intersects the gyrotron beam line at the island position on the low field side equatorial mid-plane. The angle between the incident wave vector $\left(\mathbf{k}^{i}\right)$ and the scattering wave vector $\left(\mathbf{k}^{s}\right)$ is $160^{\circ}$ and the resolved wave vector $\left(\mathbf{k}^{s}-\mathbf{k}^{i}\right)$ is approximately perpendicular to the magnetic field. Note that the peak signal in most channels reaches up to $10 \mathrm{MeV}$ which is more than 3 orders of magnitude larger than the ECE level $(1 \mathrm{keV})$ and 4-6 orders of magnitude larger than the CTS signal $(1-100 \mathrm{eV})$ from ordinary thermal fluctuations. Presence of such anomalous signals are a nuisance for proper operation of the feedback system and for CTS measurements, and it is therefore essential to understand their origin.

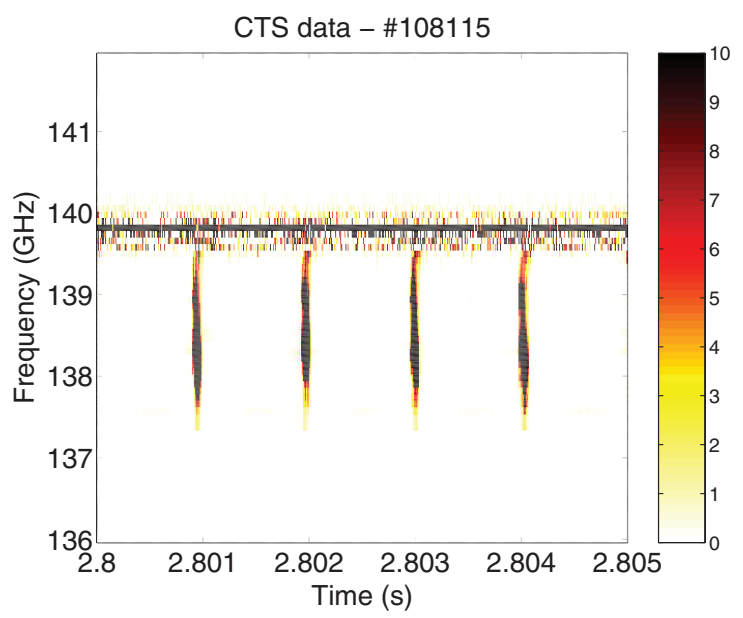

FIG. 3. Contour plot of receiver data (in $\mathrm{MeV}$ ) during a short time window at a line-averaged electron density of $2.3 \times 10^{19} \mathrm{~m}^{-3}$. The $\mathrm{O}$-point of a rotating island passes the gyrotron beam (and the receiver line of sight) at the times of maximum signal.
Channel $33(139.8 \mathrm{GHz})$ is sensitive to the gyrotron power. The spectral power density in this channel scales like the gyrotron power, and the signal level does not depend on the electron density. In principle the anomalous signal could originate from the gyrotron if spurious modes are excited in the gyrotron cavity. The ratio between spectral power density of the main gyrotron frequency and the spectral power density of the anomalous signal should then be similar regardless of the system setup. To investigate the origin of the anomalous strong signals, a number of discharges were performed where the CTS transmission line was blocked with a metal plate. By blocking the transmission line, the signal in the receiver will be dominated by gyrotron stray radiation from the tokamak hall since the receiver horn was not blocked. The signal level in channel 33 was reduced by a factor about 200 compared with that in a reference discharge with a normal view to the plasma. At the same time the signal level in all other channels was reduced by many orders of magnitude. Since the level of the anomalous signal was reduced significantly more than the gyrotron stray radiation level, this indicates that the anomalous signal is not a part of the gyrotron stray radiation.

In another discharge the rotation angle of the CTS receiver line of sight was changed gradually during the gyrotron probe time. All plasma parameters were kept constant, and the line-averaged density was $2.5 \times 10^{19} \mathrm{~m}^{-3}$. The inserted plot in Fig. 4 shows the waveform of the viewing angles. The rotation angle is changed linearly from 2.2 to $4.2 \mathrm{~s}$. Since the rotation and elevation angles cannot be changed individually, a small variation in the elevation angle is also present. The spectral power density in the channel sensitive to the gyrotron power $(139.8 \mathrm{GHz})$ has a maximum at $3.8 \mathrm{~s}$ but signal is present during the entire ECRH phase from 1.9 to $4.2 \mathrm{~s}$ (see Fig. 4). The signals in the other channels are localized in time and have a maximum when the receiver line of sight intersects the gyrotron beam at around $3.4 \mathrm{~s}$. Figure 4 also shows time traces of two other channels, one at $139.3 \mathrm{GHz}$ and one at $140.5 \mathrm{GHz}$. These two channels peak before the channel monitoring the gyrotron, and the signal is down to much lower levels when the channel monitoring the gyrotron peaks. This

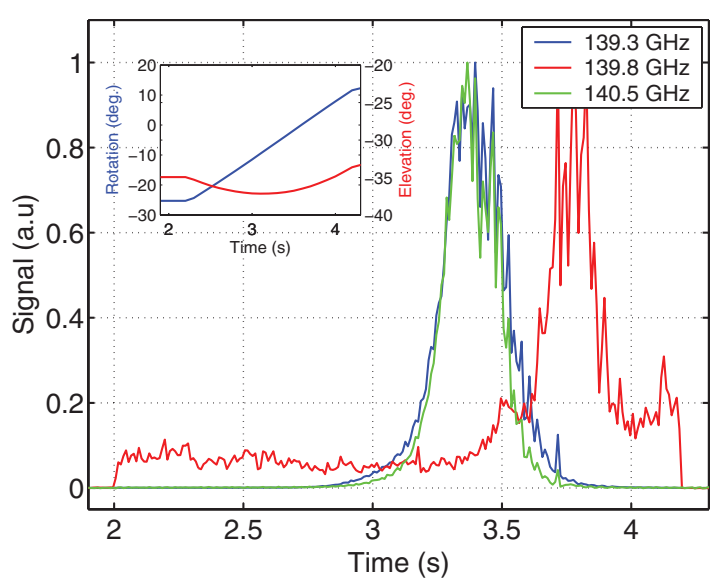

FIG. 4. Time traces of three channels from the CTS receiver from TEXTOR $\# 108101$. The data are averaged over a $10 \mathrm{~ms}$ time window. The channel of center frequency $139.8 \mathrm{GHz}$ is sensitive to the gyrotron power. The inserted figure shows the viewing angles as a function of time. 
confirms that the anomalous signal originates from scattering along the gyrotron beam and not from the gyrotron stray radiation.

In discharges with a gradually changing rotation receiver angle, the receiver elevation angle determines at which radial position the receiver beam will intersect the gyrotron beam. When the intersection position is set close to the island position on the low field side a clear peak is observed in the signal at the intersection time. No clear peak is observed in the signal, during a receiver rotation scan, when the intersection position is set to the plasma center. This suggests that the signal originates from the island position. In these discharges the line-averaged density was kept at $2.5 \times 10^{19} \mathrm{~m}^{-3}$.

An additional spectrometer, sharing the transmission line with the gyrotron, measures the back-scattered radiation. ${ }^{9}, 10$ This in-line receiver samples a down-converted signal directly with a fast digitizer, and spectra are generated by Fourier analysis. The in-line receiver has a high frequency resolution $(0.5 \mathrm{MHz})$ compared with the CTS receiver whereas time resolution of the CTS receiver is higher than that of the in-line system. Here we compare the signal measured by the in-line receiver with a time resolution of $1 \mathrm{kHz}$ to that of the modified CTS receiver.

In discharge 108115 a gyrotron power of $600 \mathrm{~kW}$ is injected into a plasma with a rotating island. The lineaveraged electron density is ramped from 1.5 to $3.4 \times 10^{19}$ $\mathrm{m}^{-3}$ but here we focus on low line-averaged densities up to $1.8 \times 10^{19} \mathrm{~m}^{-3}$. In the beginning of the density ramp a signal appears in both receivers. A well defined signal with a frequency of around $139 \mathrm{GHz}$ is seen in the CTS receiver as well as in the in-line receiver at around $t=2.0 \mathrm{~s}$ (Fig. 5). This corresponds to a line-averaged density of $1.5 \times 10^{19} \mathrm{~m}^{-3}$. The frequency of the signal decreases as the density is increased, and at a line-averaged density of $1.8 \times 10^{19} \mathrm{~m}^{-3}$ at $t=2.3 \mathrm{~s}$ the frequency has dropped by approximately $0.5 \mathrm{GHz}$. Similar signals, with decreasing frequency for increasing density, are present at around $138 \mathrm{GHz}$ and $137.5 \mathrm{GHz}$ in both systems. The width of the $138.5 \mathrm{GHz}$ signal from $t=2.1 \mathrm{~s}$ to $t=2.3 \mathrm{~s}$ differs in the two receivers. When looking at a close up of the CTS signal at $t=2.2 \mathrm{~s}$ (Fig. 5(c)) a strong variation of the signal in phase with the island period is observed at $138.5 \mathrm{GHz}$. The sampling frequency of the in-line system and the frequency of the DED differs by $26 \mathrm{~Hz}$ which cause a modulation of the in-line data due to island passages.

In the frequency range $136 \mathrm{GHz}$ to $137 \mathrm{GHz}$ a very pronounced signal is present in the in-line data from $t=2.0 \mathrm{~s}$ to $t=2.3 \mathrm{~s}$. At this frequency range, signal in the CTS receiver is only present after $t=2.1 \mathrm{~s} \mathrm{(see} \mathrm{Fig.} \mathrm{5(c))} \mathrm{and} \mathrm{is} \mathrm{correlated}$ to the passage of the island O-point. The scattering volume of the in-line system covers the entire tokamak cross section. Contrarily, the scattering volume of the CTS receiver has a spatial extent of about $10 \mathrm{~cm}$ and is placed on the plasma low field side at the island position. The signal difference in the two systems might very well be due to scattering taking place at different radial locations along the gyrotron beam.

The lower hybrid (LH) frequency in the plasma center, $f_{L H}=\sqrt{\left(f_{c e} f_{c i}\right) /\left(1+f_{c e}^{2} / f_{p e}^{2}\right)}$, changes from 0.58 to $0.74 \mathrm{GHz}$ during the time from $2.0 \mathrm{~s}$ to 2.3 s. $f_{c e}, f_{c i}, f_{p i}$,

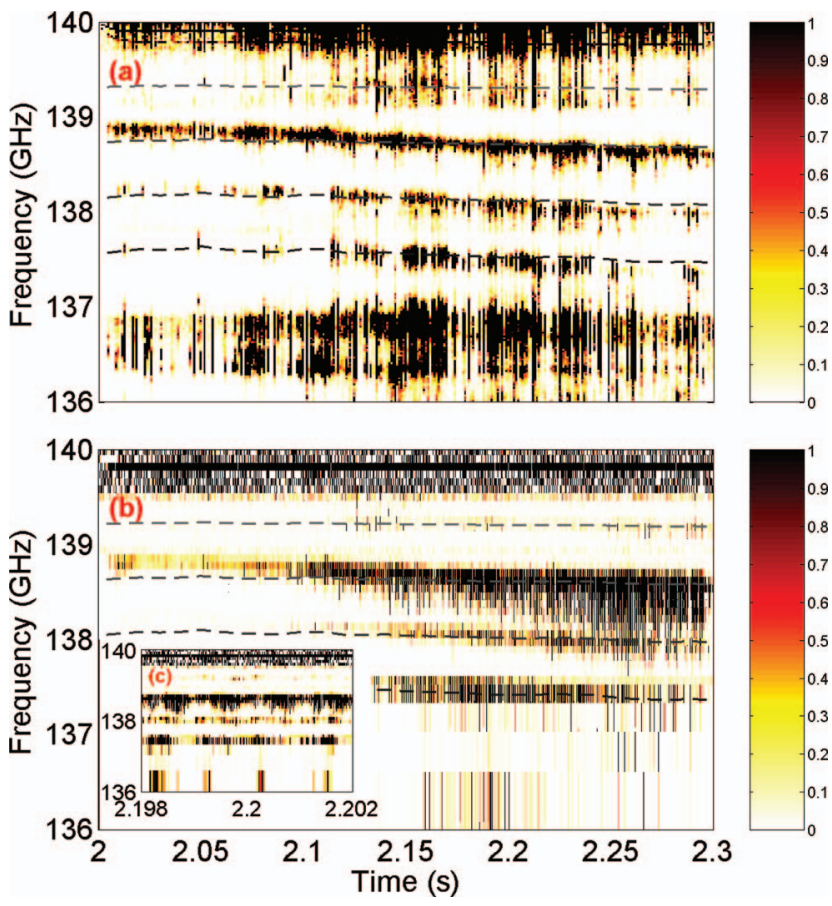

FIG. 5. (a): Contour plot of inline radiometer data (a.u.) as a function of time and frequency. (b): Contour plot of CTS receiver data (a.u.) as a function of time and frequency. (c): Zoom of (b) in a time window of 4 island periods. TEXTOR discharge 108115. The dashed lines represent the difference between the gyrotron frequency and (from top to bottom) the central LH frequency, the central LH second harmonic, the central LH third harmonic and the central LH fourth harmonic.

and $f_{p e}$ are the electron cyclotron frequency, ion cyclotron frequency, ion plasma frequency, and the electron plasma frequency, respectively. The gyrotron frequency subtracted $n \times f_{L H}$ is shown in Fig. 5 for $n=1,2,3,4$ and show good agreement with the measurement from the two independent systems. No signal is observed above the gyrotron frequency in the CTS receiver for this density range. This supports the theory that the observed signals may be associated with the parametric decay instability. The spatial origin of this signal for these low densities was not investigated experimentally.

\section{CONCLUSION}

The radiometer used by the fast-ion CTS system on TEXTOR has been modified to detect strong signals in the frequency region around $140 \mathrm{GHz}$ to characterize radiation which could originate from parametric decay. The receiver front is replaced by new notch filters, a high pass filter, and a mixing stage. Attenuation units in the transmission line are used to attenuate the signal which did otherwise saturate the receiver. The attenuation units are calibrated by viewing thermal ECE from the plasma, and the receiver without additional attenuation is cross-calibrated to the ECE diagnostic and incoherent Thomson scattering.

We compare data from the modified CTS receiver receiver with those from a spectrometer integrated in the gyrotron transmission line. The measured data show similar trends with respect to time, density, and frequency even though the scattering angles and measurement volumes of the 
two systems are different. Nevertheless this shows that both receivers deliver consistent data when operated similarly.

The fast-ion CTS receiver on ASDEX Upgrade ${ }^{23,24}$ is currently being upgraded to operate in the frequency ranges around $105 \mathrm{GHz}$ as well as $140 \mathrm{GHz}$ by two different front ends. The TEXTOR and ASDEX Upgrade systems are expected to increase the knowledge of parametric decay and scattering off tearing modes which might have a bearing for possible CTS operating scenarios on ITER. ${ }^{25}$

\section{ACKNOWLEDGMENTS}

The contributions of all team members of TEXTOR are gratefully acknowledged. A. Kramer-Flecken and G. W. Spakman are acknowledged for the loan of essential equipment. This work, supported by the European Communities under the contract of Association between EURATOM and DTU, FOM, and FZJ, was carried out within the framework of the European Fusion Programme. The views and opinions expressed herein do not necessarily reflect those of the European Commission.

${ }^{1} \mathrm{~J}$. Wesson, Tokamaks, 4th ed. (Oxford University Press, 2011).

${ }^{2}$ T. Hender, J. Wesley, J. Bialek, A. Bondeson, A. Boozer, R. Buttery, A. Garofalo, T. Goodman, R. Granetz, Y. Gribov, O. Gruber, M. Gryaznevich, G. Giruzzi, S. Günter, N. Hayashi, P. Helander, C. Hegna, D. Howell, D. Humphreys, G. Huysmans, A. Hyatt, A. Isayama, S. Jardin, Y. Kawano, A. Kellman, C. Kessel, H. Koslowski, R. L. Haye, E. Lazzaro, Y. Liu, V. Lukash, J. Manickam, S. Medvedev, V. Mertens, S. Mirnov, Y. Nakamura, G. Navratil, M. Okabayashi, T. Ozeki, R. Paccagnella, G. Pautasso, F. Porcelli, V. Pustovitov, V. Riccardo, M. Sato, O. Sauter, M. Schaffer, M. Shimada, P. Sonato, E. Strait, M. Sugihara, M. Takechi, A. Turnbull, E. Westerhof, D. Whyte, R. Yoshino, H. Zohm, and the ITPA MHD, Disruption and Magnetic Control Topical Group, Nucl. Fusion 47, S128 (2007).

${ }^{3}$ U. Samm, Fusion Sci. Technol. 47, 73 (2005)

${ }^{4}$ B. A. Hennen, E. Westerhof, P. W. J. M. Nuij, J. W. Oosterbeek, M. R. de Baar, W. A. Bongers, A. Bürger, D. J. Thoen, and M. Steinbuch, Plasma Phys. Controlled Fusion 52, 104006 (2010).

${ }^{5}$ J. W. Oosterbeek, A. Bürger, E. Westerhof, M. R. de Baar, M. A. van den Berg, W. A. Bongers, M. F. Graswinckel, B. A. Hennen, O. G. Kruijt, J. Thoen, R. Heidinger, S. B. Korsholm, F. Leipold, and S. K. Nielsen, Rev. Sci. Instrum. 79, 093503 (2008).

${ }^{6}$ M. Porkolab, Nucl. Fusion 18, 367 (1978).

${ }^{7}$ V. Erckmann and U. Gasparino, Plasma Phys. Controlled Fusion 36, 1869 (1994).
${ }^{8}$ S. B. Korsholm, H. Bindslev, F. Meo, F. Leipold, P. K. Michelsen, S. Michelsen, S. K. Nielsen, E. L. Tsakadze, P. Woskov, E. Westerhof, J. W. Oosterbeek, J. Hoekzema, F. Leuterer, and D. Wagner, Rev. Sci. Instrum. 77, 10E514 (2006).

${ }^{9}$ D. J. Thoen, W. A. Bongers, E. Westerhof, J. W. Oosterbeek, M. R. de Baar, M. A. van den Berg, V. van Beveren, A. Bürger, A. P. H. Goede, M. F. Graswinckel, B. A. Hennen, and F. C. Schüller, Rev. Sci. Instrum. 80, 103504 (2009).

${ }^{10}$ W. A. Bongers, V. van Beveren, D. J. Thoen, P. J. W. M. Nuij, M. R. de Baar, A. J. H. Donné, E. Westerhof, A. P. H. Goede, B. Krijger, M. A. van den Berg, M. Kantor, M. F. Graswinckel, B. A. Hennen, and F. C. Schüller, Rev. Sci. Instrum. 82, 063508 (2011).

${ }^{11}$ E. Westerhof, S. Nielsen, J. Oosterbeek, M. Salewski, M. De Baar, W. Bongers, A. Bürger, B. Hennen, S. Korsholm, F. Leipold, D. Moseev, M. Stejner, and D. Thoen, Phys. Rev. Lett. 103, 125001 (2009).

${ }^{12}$ E. Gusakov, Phys. Rev. Lett. 105, 115003 (2010).

${ }^{13}$ E. Gusakov and A. Popov, Nucl. Fusion 51, 073028 (2011).

${ }^{14}$ E. Z. Gusakov and A. Y. Popov, JETP Lett. 91, 655 (2010).

${ }^{15}$ V. I. Arkhipenko, E. Z. Gusakov, L. V. Simonchik, and M. S. Usachonak, Europhys. Lett. 93, 25001 (2011).

${ }^{16}$ H. Bindslev, S. Nielsen, L. Porte, J. Hoekzema, S. Korsholm, F. Meo, P. Michelsen, S. Michelsen, J. Oosterbeek, E. Tsakadze, E. Westerhof, and P. Woskov, Phys. Rev. Lett. 97, 205005 (2006).

${ }^{17}$ S. K. Nielsen, H. Bindslev, L. Porte, J. A. Hoekzema, S. B. Korsholm, F. Leipold, F. Meo, P. K. Michelsen, S. Michelsen, J. W. Oosterbeek, E. L. Tsakadze, G. Van Wassenhove, E. Westerhof, and P. Woskov, Phys. Rev. E 77, 016407 (2008).

${ }^{18}$ S. K. Nielsen, H. Bindslev, M. Salewski, A. Bürger, E. Delabie, V. Furtula, M. Kantor, S. B. Korsholm, F. Leipold, F. Meo, P. K. Michelsen, D. Moseev, J. W. Oosterbeek, M. Stejner, E. Westerhof, and P. Woskov, Plasma Phys. Controlled Fusion 52, 092001 (2010).

${ }^{19}$ S. Nielsen, M. Salewski, H. Bindslev, A. Bürger, V. Furtula, M. Kantor, S. Korsholm, H. Koslowski, A. Krämer-Flecken, F. Leipold, F. Meo, P. Michelsen, D. Moseev, J. Oosterbeek, M. Stejner, and E. Westerhof, Nucl. Fusion 51, 063014 (2011).

${ }^{20}$ F. Leipold, S. Nielsen, and S. Michelsen, Rev. Sci. Instrum. 79, 065103 (2008).

${ }^{21}$ W. A. Bongers, A. P. H. Goede, E. Westerhof, J. W. Oosterbeek, N. J. Doelman, F. C. Schuller, M. R. De Baar, W. Kasparek, W. Wubie, D. Wagner, and J. Stober, Fusion Sci. Technol. 55, 188 (2009).

${ }^{22}$ S. Abdullaev, K. Finken, M. Jakubowski, S. Kasilov, M. Kobayashi, D. Reiser, D. Reiter, A. Runov, and R. Wolf, Nucl. Fusion 43, 299 (2003).

${ }^{23}$ V. Furtula, M. Salewski, F. Leipold, P. K. Michelsen, S. B. Korsholm, F. Meo, D. Moseev, S. K. Nielsen, M. Stejner, and T. Johansen, Rev. Sci. Instrum. 83, 013507 (2012).

${ }^{24}$ M. Salewski, F. Meo, M. Stejner, O. Asunta, H. Bindslev, V. Furtula, S. Korsholm, T. Kurki-Suonio, F. Leipold, F. Leuterer, P. Michelsen, D. Moseev, S. Nielsen, J. Stober, G. Tardini, D. Wagner, and P. Woskov, Nucl. Fusion 50, 035012 (2010).

${ }^{25}$ M. Salewski, L.-G. Eriksson, H. Bindslev, S. Korsholm, F. Leipold, F. Meo, P. Michelsen, and S. Nielsen, Nucl. Fusion 49, 025006 (2009). 